\title{
GUATEMALA'S INDIGENOUS MATERNAL HEALTH CARE: A SYSTEM IN NEED OF DECOLONIZATION ${ }^{1}$
}

\begin{abstract}
Alicia Giralt ${ }^{2}$
El cuidado de la salud materna de las indígenas guatemaltecas: Un sistema en necesidad de descolonización

Resumen: Las tasas de mortalidad materna guatemalteca son las más altas de Centroamérica. Dichas tasas varían drásticamente entre grupos étnicos, con las más altas presentes entre mujeres rurales mayas. Mientras Guatemala se esfuerza para reducir estas cifras, la controversia se centra en comadronas tradicionales. Esta investigación estudia el papel de dichas comadronas dentro de un marco postcolonialista y descolonialista. Los resultados muestran un país bajo el legado de la colonización, manifestado en el cuerpo femenino colonizado. Un cambio de paradigma es crucial en relación con las comadronas y sus pacientes. La salud reproductiva de las mujeres indígenas no mejorará hasta que esto suceda y la atención médica sea descolonizada.

Palabras clave: maya, mujer, indígena, salud maternal, mortalidad, colonialism, postcolonialismo, descolonialismo, partera, comadrona.

Guatemala's Indigenous Maternal Health Care: A System in Need of Decolonization

Abstract: Guatemala's Maternal Mortality Ratios are the highest in Central America. These ratios vary drastically among ethnic groups, the highest occurring among rural Mayan women. As Guatemala struggles to reduce its MMRs, the controversy centers on Mayan Traditional Birth Attendants. This research investigates the role of Mayan traditional midwives within the framework of Postcolonialism. The results show a country under the legacy of colonization, manifested in the female colonized body. A paradigm shift is crucial in relation to both traditional birth attendants and their patients. Indigenous women's reproductive health will not improve until health care, a legacy of Colonialism, is decolonized.

Key words: Maya, woman, indigenous, maternal health, mortality, Colonialism, Postcolonialism, Decolonialism, midwives.
\end{abstract}

\section{Background}

In Guatemala two women die almost every day due to complications related to childbirth. In 1995, when Guatemala ended its 36-year internal armed conflict, the

\footnotetext{
${ }^{1}$ Date of reception: $27 / 10 / 2014$.

Date of acceptance: $30 / 11 / 2014$.

2 Professor of Spanish, Departmento de Lenguas Extranjeras y Directora del Programa de Estudios de la Mujer y de Género, Weber State University, Ogden, U.S.A.; \agiralt@weber.edu.
} 
Agreement on Identity and Rights of Indigenous Peoples was signed. This document confirmed a situation most people were well aware of, "The Indigenous peoples have been particularly subject to de facto levels of discrimination" (Peace 1998). Moreover, a section declared the particularly severe situation of Indigenous women, "characterized by intense poverty and exploitation," and provided a legal framework to alleviate this problem. Seventeen years later not much has changed. Mayan communities continue to struggle under the weight of the heritage of colonialism. The UN Office of the High Commissioner for Human Rights stated, "Guatemala enjoys a rising economy that would guarantee the well-being of all its citizens if its wealth were distributed equally. Instead, Guatemala has one of the most unequal distributions of wealth in the world" (2009). This social and economic disparity is most evident in the health of Guatemalan Indigenous women, specifically in their Maternal Mortality Ratio (MMR). According to a study conducted by the Ministry of Planning and Programming of the Presidency (Secretaría de Planificación y Programación de la Presidencia) (SEGEPLAN), under the Ministry of Public Health and Social Assistance (Ministerio de Salud Pública y Asistencia Social), while Ladino (Amerindian-Spanish or of European heritage) women who lived in metropolitan areas showed in 2009 a 65.88 MMR per 100,000 live births, Mayan women who lived in the rural area of Izabal suffered a 301.8 MMR (SEGEPLAN 2011 B: 13), almost five times higher than the MMR of Ladino women in metropolitan areas. In 2013, the estimated average MMR for the country was 140 deaths per 100,000 births. As a frame of reference, Spain's MMR was 4, and the United States' was 28 (Global Health Observatory 2014).

In 2010 then President Colom reiterated his country's determination to reach the United Nation's Millennium Development Goals, including goal 5: To improve maternal health by 2015 by reducing the MMR by 75\% (Secretaría de Planificación y Programación de la Presidencia República de Guatemala/ Secretariat of Planning and Programming of the Presidency of Guatemala, SEGEPLAN 2010). Nevertheless, Guatemala continues to struggle to reduce its MMR and to increase the proportion of births attended by medical personnel, a situation considered crucial to save mothers' lives. In 2010, the Guatemalan government undertook a study to set the maternal-death baseline 
and to identify its causes and characteristics. This study was critical of the current situation, stating "the Peace Accords of 1996 assumed the commitment to reduce Maternal Mortality by $50 \%$ by 2000, taking 1995 as the base year, but eleven years later, this commitment has not been satisfied" (SEGEPLAN/MSPAS 2010: 8).

As mentioned before, Guatemala's average $140 \mathrm{MMR}$ is the highest in Central America. MMRs in the country range from 34.3 MMR in Zacapa, with 99.6 percent Ladino population (Cifras para el Desarrollo Humano n.d.), to 301.8 in the area of El Estor, in the department of Izabal ${ }^{3}$, where the majority of the residents are Mayan. The MMR for women living in the Sololá Department, where this study was conducted, was 113 MMR in 2011 (SEGEPLAN 2011 A).

The National Study of Maternal Mortality (SEGEPLAN 2011 A) stated that the two main causes of death were attributed to hemorrhage $(53.3 \%)$ and infection $(14.4 \%)$, followed by hypertension (12.1\%) and abortion (9.5\%). The same study indicated that most deaths were suffered by indigenous women (71.2\%) who lived in rural areas (66.3 $\%)$ and had had between one and three children (48.3\%).

One could wonder how hemorrhage can be the reason for over half the number of maternal deaths, given that in a medical setting stopping a hemorrhage is generally not a difficult task. The National Study of Maternal Mortality explains this phenomenon through a series of four delays in accessing health care that women experience (SEGEPLAN 2011 A). The first delay occurs when women, their families, and even their communities are unaware that the condition of the parturient requires seeking immediate medical help. The second delay occurs when the future mother is aware of a problem, but due to the lack of empowerment some women experience, she is unable to seek help. In other cases, perhaps her husband or mother-in-law refuses to let her go to the hospital. During the third delay, everyone agrees the future mother should go to a hospital, but there's no transportation. Finally, during the fourth delay, the parturient arrives to the

\footnotetext{
${ }^{3}$ Administratively, Guatemala is divided into 22 departments.
} 
hospital, but the facility lacks the means to alleviate the mother's medical condition (SEGEPLAN 2011 A).

According to the Ministry of Public Health and Public Assistance, much is being done to eliminate these four delays. In line with this objective, the Ministry of Public Health proposed one way to eliminate Delay 1: ensuring that women are treated by biomedical professionals, instead of being treated by Mayan Traditional Birth Attendants, whom biomedical professionals and some government representatives consider unqualified to assist pregnant women.

The controversy surrounding Mayan Traditional Birth Attendants is greater in rural areas, since this is primarily where these women work. Biomedically-trained professionals tend to frown upon the care provided by these iyoma [iyom in the singular form]. Given that most pregnancies in rural areas are assisted by iyoma, the Health Ministry has made iyoma partly responsible for the country's MMR (Julajuj 2010) and so have some scholars (Lang and Elkin 1997). These types of assertions reveal the attitudes of some biomedical practitioners and their lack of trust in iyoma, a reflection of a postcolonial health care system where the knowledge of the Other is disregarded and a result of ignorance and witchcraft. When the Other is poor, Indigenous, and female, it is even easier to discriminate against her.

In Guatemala, as in many other communities, several types of professionals assist women during childbirth. To avoid confusion, in this text the terms iyom and iyoma are used to identify women who have become birth attendants through a gift from the spirit world. An ancient belief in many Mayan cultures is that spirits such as deceased iyoma visit girls and young women in their dreams to teach them their skills. "Partera" is the term the Tz'utujil community uses to describe birth attendants who have not received a gift from the spirits. Instead, they have learned their profession either by assisting other parteras or iyoma, or through training imparted by an NGO or government program. This text will use "partera" according to this definition. The government expects iyoma to attend workshops and receive biomedical training, but even when they have, this text will refer to them as iyoma to identify birth attendants who claim to have received a gift from 
the spirit world. Since before the European invasion, women and whole communities have considered iyoma some of the most trusted and respected members of their societies, and, oftentimes even today, they are the only health-related resource for rural pregnant women and newborns. Almost 500 years after Pedro de Alvarado conquered the K'iché and the Kaqchikel peoples of what would be known as Guatemala, and close to 200 years since the country declared its independence from Spain, Mayan women, for the most part, are still viewed as the Other. That is, as weak, ignorant, and superstitious; someone existing in the periphery of society whose health does not matter as much as that of their white and mestizo sisters.

This study looks at Guatemala's efforts, and failures, to reduce its MMRs, the role iyoma play in the health of their patients today, and the relationship between iyoma and biomedical professionals, with a focus on Tz'utujil ${ }^{4}$ communities located on the south side of Lake Atitlan. The results show a country still largely influenced by biopolitics and the legacy of colonization, strongly manifested in the ongoing colonization of the female body. Nowhere is this more visible than in the high number of Indigenous women who die due to pregnancy, whether it be before, during or right after childbirth.

\section{Methods}

To provide background and context for Guatemala's MMRs, a survey of related documents was conducted. These documents were created by governmental institutions such as the Ministry of Public Health and Social Assistance, the Presidential Secretary of Women of Guatemala, the Secretariat of Planning and Programming of the Presidency, and by the United Nation's Human Rights. Relevant academic literature and media accounts were also surveyed.

\footnotetext{
${ }^{4}$ The Tz'utujil are one of the 21 Mayan ethnic groups who live in Guatemala.
} 
Within the framework of postcolonial and decolonization studies, to obtain the viewpoint of Mayan women, methods in this investigation included the analysis of semistructured interviews with 21 Mayan-Tz'utujil mothers, six Mayan-Tz'utujil iyoma ${ }^{5}$ and the director of Mayab' Ixoqi,' an organization that provides technical support to the council of iyoma and therapists of Mayan-Tz'utujil communities.

To obtain the viewpoint of local mothers, a school in San Pedro La Laguna summoned Tz'utujil mothers to volunteer to participate in purposive, semi-structured interviews. The ers' interviews held with the mothers were held over two summers. In total, twenty-one women participated. All the women lived in San Pedro La Laguna, except one who lived in neighboring San Juan La Laguna. The method and questions for mothers had IRB approval. The questions were centered on who had helped them when they were pregnant, where they had delivered their children, why local women avoided the hospitals, and about their experiences with iyoma and parteras. In cases where the participants were illiterate, informed consent forms were read to them and their verbal approval was obtained. All the interviews lasted under two hours and were video recorded for later analysis. The participants ranged from 21 to 51 years-old. The women had 80 children in total, an average of 3.8 children per woman. Overwhelmingly, the women lived in poverty, and although they worked, they did so in the informal economy, with occupations such as making tortillas in their kitchens and selling them from home to home, beading bracelets and necklaces to sell to tourist, or selling snacks to children when they left school. Only two participants worked in the formal economy. Their husbands also had temporary jobs. Four women were single mothers. All the participants spoke Tz'utujil $^{6}$ and most had limited knowledge of Spanish. An interpreter collaborated with the research assisting not just with the meaning of words, but also explaining some cultural concepts.

\footnotetext{
${ }^{5}$ This number is small, but given the size of San Pedro, about 11,500 residents (Instituto Nacional de Estadística, 2014), it seems representative. The exact number of iyoma in this town is unknown. Even iyoma tend to be aware of only the ones practicing in their neighborhoods.

${ }^{6}$ Tz'utujil is one of Guatemala's 21 formally recognized Mayan languages. It is spoken by about 80,000 people.
} 
The same school invited iyoma to attend at later times. Iyoma's interviews took place over four years of summer fieldwork. Two iyoma had a very basic knowledge of Spanish: they could understand it, but did not feel comfortable speaking it. In these cases a trusted Tz'utujil interpreter was employed. As in the case with the mothers, the method and questions for iyoma had IRB approval. When the iyoma were illiterate, informed consent forms were read and their verbal approval was obtained. Their names have been changed or withheld to protect their privacy. Iyoma were asked to explain how they knew their role would be to help pregnant women, and how they obtained their skills. Also, they were asked to describe their experiences with government-required training and workshops. Finally, they were also asked to share the reasons their patients had given for their refusal to go to hospital.

\section{Findings}

All the mothers, except for one, had been taken care of by iyoma. This group of women did not like parteras, expressing that they were not "real." They considered them impostors because their techniques did not come from the spirits. All participants, except for two, had delivered at home with their iyom. One woman had her child in a hospital, and the other subject had given birth by cesarean section in a local clinic attended by two foreign doctors. This procedure took place in 2013 and the clinic had since closed. Therefore, this option is not available any more for local pregnant women who want to deliver in their hometown.

As stated above, all the iyoma claimed to have learned their profession through dreams brought on by spirits, just as studies on this topic also report. According to MayanTz'utujil traditions, spirits preselect women who will eventually become iyoma (Paul L. 1975, Paul L. \& Paul 1975, Cosminsky 2001, Hurtado \& Sáenz de Tejada 2001, Berry 2006, Rogoff 2011, de León 2012). Given the lack of knowledge about this situation in the Western world outside the field of Anthropology, it is worthwhile to describe it in 
more detail. In Mayan-Tz'utujil tradition girls born with a distinctive clear white membrane ${ }^{7}$ over their heads are destined to become iyoma. These girls are also born on a specific date of the Mayan calendar.

Being selected as an iyom is considered an honor by the community and a gift from the spirits and $\mathrm{Ajaw}^{8}$-God. As girls enter their teenage years, spirits teach young iyoma through dreams how to take care of pregnant women. An iyom who experienced these circumstances is sixty-five year old, Matea. ${ }^{9}$ During a conversation (personal communication, July 2011), she explained that when she was 10 years old she started having dreams of her massaging a woman's stomach, and was troubled because in her dreams there was a lot of blood. When she asked her mother, she was told that Matea was dreaming about a delivery. Her mother proceeded to explain to Matea how she had been born predestined to become an iyom. Fifty-eight year old Marta had a very similar experience, except that when she tried telling her mother, the mother got very upset, scolded Marta and told her that such type of conversation was not appropriate for young girls (personal communication, July 2011). Sex and pregnancy were taboo subjects for people their generations, although this is slowly changing.

Once they become adults, if iyoma decline in their gift, and refuse to exercise their duty, they believe they will be harmed by misfortunes -including disease and death- that will affect them and their families. Some might refuse because iyoma are not allowed to charge for their services, but can only accept what the parturients and their families give them voluntarily. As iyoma near the time to start putting into practice their gifts (usually after they become mothers themselves), they believe spirits guide them to the tools they will need. Thus, iyoma believe that when they find small knives or scissors on the roads or fields, those items are provided by the spirits because they will need them, for example,

\footnotetext{
${ }^{7}$ Interestingly enough, this membrane, or veil as the Tz'utujil women call it, is described in a similar way to a "caul," which other cultures believe it brings mainly good luck to those born with it, or may keep them from drowning. See for example, Barbara Newman and Leslie Newman. 1939. "Some birth customs in East Anglia." Folklore 50 2: 176-187, about a community in England, and C. C. Baines. 1950. "Children Born with a Caul," Folklore. 61 2: 104.

${ }^{8}$ Ajaw is the name given to the Creator by the Tz'utujil. Many iyoma call it "Ajaw-God," which highlights the integration of Indigenous and Christian beliefs.
} 
to cut the umbilical cord, and other similar actions. Iyoma also dream about the use of plants for medicinal purposes, whether to be used in baths, infusions, or creams. It is crucial to realize that for her patients and other community members, an iyom is much more than a health provider. They are sacred specialists, as Louis Paul and Benjamin Paul (1975) have called them, and as such they are treated as well-respected members of the community. Barbara Rogoff writes that an iyom "is a divine healer who mediates between the supernatural world and the ordinary world, protecting the hazardous passage of souls as they emerge from the world of the womb" (2011: 18).

Mayan-Tz'utujil women trust iyoma more than they trust biomedical personnel (Giralt 2012). Iyoma provide pre- and post-partum care, as well as care for the newborn. Pregnant women will follow their instructions. However, there is advice many pregnant women either won't take, or take very reluctantly. Even when iyoma advise their patients to go to a hospital because of complications, pregnant women are reluctant to do so. They offer multiple reasons for this refusal. One of the reasons is that at the hospital they are discriminated and humilitated because they are Maya and do not speak Spanish well. Another reason is related to the education Mayan women have received about how to dress in public and when to show (or not to show) their bodies. As a group, they are very modest. Marta (personal communication June 2010) explained that doctors and nurses do not respect their patients' wish for privacy, and force them to take off their clothes, something they are not used to doing in front of strange men, since they don't visit doctors often and iyoma are always female.

To pregnant women worried about what to expect when giving birth, iyoma provide assurance that everything is going to work out fine (Schieber 2008). Consequently, future mothers are more relaxed when their iyom is present. When considering about whether going to hospital, pregnant women want their iyoma to help them with the delivery, but in many cases hospitals do not allow them in. Commonly, only one person is allowed to accompany the patient during childbirth, and the expectant mother has to choose between her iyom and her husband. Another reason women forego when going to the hospital is that many have small children at home and being away from them is a stressful situation. Having their other children nearby, which is the norm when iyoma attend a delivery at 
home, helps women to be relaxed (Reynolds 2010). Sometimes, pregnant women choose not to go to hospital at all.

Additional reasons women have given for avoiding hospital care include condescending attitudes of the health care providers, and refusal by their husbands to let them go (Schieber 2008); and perception of poor quality of care, limited hours of service, and even poor or non-existent access to hospitals (Goldman 2003). In some cases, although transportation to a health care facility is available, patients and iyoma cannot afford to pay for a taxi or a bus. This situation fits under the third delay.

The relationship between mother-in-law and future mother also plays a part. As a newlywed female moves into her husband's family home, she is expected to obey his mother. Older women who had their children at home want their grandchildren to be born at home too. The expected submission of the soon-to-be mother keeps her from asserting her wishes. Consequently, even if she wishes to deliver in a hospital, when her mother inlaw or husband prefer the home, chances are the child will be born at home. This is the situation reflected in the second delay, as mentioned before.

Other reasons for avoiding the hospital are related to ingrained traditions. After the birth of the child, iyoma take the mother to the temascal (traditional Mayan steam bath) to bring heat into her body. Iyoma also serve chamomile or cumin tea to the mothers. These activities are not allowed in a hospital setting. Additionally, Mayan women believe that burying the placenta protects the mother and the newborn, and consequently they perform this ritual after delivery. However, hospitals do not allow patients to take their placentas home.

Another disadvantage of giving birth at the hospital without their iyoma is that no one will be able to read the signs for gifts that the newborn might bring. Parents will not know how to prepare the child for her/his ${ }^{10}$ future. This consequence of having a child in the hospital is thought to bring many hardships on the child as s/he becomes an adult

\footnotetext{
${ }^{10}$ Although just women become iyoma, gifts of the spirit world are given to both male and female. Men and women can receive skills to become bonesetters, healers of the evil eye, and others health-care practitioners (Giralt 2012).
} 
because s/he would act as if refusing the gift, when in reality the adult would just be unaware of this destiny. Unhappiness, illness, or death may come to this young adult, ${ }^{11}$ or to those close to him/her. Finally, according to iyoma, hospitals do not take into consideration the spiritual and psychological well-being of the mother, something iyoma do (Gran Confederación de Consejos de Principales Ajq'iab' Originarios Mayab' de Guatemala 2010). It is clear that when women feel so much animosity toward hospitals, the ability of iyoma to diminish maternal deaths is small.

\section{Iyoma and Biomedical Professionals}

The relationship between iyoma and biomedical professionals is generally conflictive. In rural areas, iyoma are Indigenous women who tend to be poor and illiterate. They experience a triple subalternity based on gender, ethnicity and class, which explains their continuous low status under patriarchy in a postcolonial society. Nevertheless, this triple condition is not mentioned by the powerful elite when it justifies its rejection of iyoma, who have limited proficiency in Spanish, practically a lack formal training, and thus are not considered as an integral part of the Guatemalan Health System (Schieber, 2008). Some policy makers have labeled them as "untrainable" (Chary, A., et al. 2013). To these situations, one must add that Mayan women have taken on these professions because they believe they were told to do so in dreams, which is ridiculed by those invested in the Western way of acquiring knowledge. Although this latter reason does not show up in studies as a source of contention, it does in private conversations with biomedical professionals, who find it difficult to respect as professionals those who claim to have received their training through contact with the spirit world.

Since the Spanish invasion, Mayan spirituality has been labeled as witchcraft and superstition and it has been easy for those not practicing it to disregard and ridicule

\footnotetext{
11 This situation is not definitive. Mayan societies have other sacred specialists who can tell people in similar circumstances what their gifts are.
} 
phenomena related to its beliefs. Although not all iyoma practice Mayan spirituality (a number of them are Catholic or Evangelical), many embrace the syncretism of Mayan and Catholic beliefs. The Agreement on Identity and Rights of Indigenous Peoples states that Mayan spirituality and knowledge should be respected, and spaces should be provided for ceremonies, but these affirmations have not reached all biomedical practitioners yet.

As the government demands that all traditional birth attendants receive specific training, the iyoma interviewed for this study and who spoke Spanish said they appreciated being taught how to recognize problems, such as hypertension. For the three iyoma who only had a rudimentary knowledge of Spanish, it was difficult to understand what was being said in the trainings. Clearly, for iyoma to fully take advantage of any training program, the instruction must be done in a language the students will understand. As Lang pointed out, "Programs must be tailored appropriately to the learners. Traditional iyoma need programs designed for uneducated, illiterate, and elderly learners, with classes taught in their primary language" (Lang and Elkin 1997: 30). Being aware even minimally of the iyoma's backgrounds, it is easy to see why the training programs have not been successful. However, the failure of the training programs goes beyond not being linguistically appropriate. Some iyoma have reported that trainers threaten them. When iyoma were instructed to refer their patients to the hospital, some of them were told they would be punished with 50 years in jail if a newborn died under their care (Gran Confederación de Consejos de Principales Ajq'ab' Originarios de Mayab' de Guatemala 2010). Other iyoma have received non-specific threats, such as a possible monetary sanctions if the mother dies while giving birth or shortly afterwards (personal communication July, 2010). These types of behaviors do nothing to improve the relationship between hospital personnel (those in power) and Indigenous women. This is especially clear when one takes into consideration that doctors and nurses tend to be Ladinos. Matea explained that although her trainer had insisted she had to take her patients to the hospital, she was afraid to do so "because they are Ladinos and do not treat the Maya well." Her experience with hospital personnel is shared by the other iyoma interviewed. They report that if their patients are waiting to be assisted and a Ladino 
woman comes in, the Maya women are made to wait and the Ladino sees the doctor first. Iyoma also reported that the respect they experience in their communities is not transferred to the hospital. They are scolded as if they were little children, a postcolonial behavior in place since Indigenous people were dominated by colonizers, who justified their actions as being necessary since Indigenous people were ignorant and needed to be told what to do.

Having experienced discrimination at the hospital, Matea was reluctant to take her patients there, although in some cases she knew she should in order to prevent the likelihood of death. She said she prayed to Ajaw-God to give her strength to go through the hospital doors. Always concerned about the well being of her patients, she said she has now established a good relationship with some of the doctors, and is allowed to help in the delivery of her patients. Her situation is not common, though. Matea has been able to assert herself because she can express herself in Spanish and because she has a strong personality. Any training program must recognize that sometimes, iyoma are not used to interacting with people outside their communities and feel uncomfortable when put in a situation to do so, specially when the iyoma do not speak Spanish and have suffered the effects of racial discrimination.

\section{Political Context}

Guatemala's efforts to improve maternal care are coming from several fronts, primarily government institutions and grass-roots organizations. In 2009, the Unidad de Atención de la Salud de los Pueblos Indígenas e Interculturalidad (Unity of Attention to Health Care of Indigenous People and Interculturalism) was funded with the mission to strengthen and promote Indigenous health practices. A year later, the Ley para la Maternidad Saludable (Law for Safe Motherhood) was signed, declaring that safe motherhood was an issue of national emergency (Centro Nacional de Análisis y Documentación Judicial 2010). The law’s principles are accessibility, gratuity, equity and 
respect for multiculturalism. Article 4.d. states, "neonatal maternal Health Services will be provided ensuring respect for cultural identity, values and customs of the communities." Furthermore, it stipulates that attention to mothers will be in their native language. Another aspect of concern to mothers and iyoma also addressed is the birthing position during delivery: allowing mothers to choose between the traditional Western position and the Mayan crouching or standing positions. According to SEGEPLAN (2014: 19), the number of hospitals allowing mothers to give birth while in a vertical position increased during $2012 .{ }^{12}$

Article 17 of the Law for Healthy Motherhood specifies, "For iyoma, the Ministry of Health and Welfare shall develop, in coordination with organizations of iyoma, a policy that includes defining the role of iyoma, their functions, the relationship with health services and establish a transition program for the training of iyoma trained and certified at a technical level"13 (Centro Nacional de Análisis y Documentación Judicial 2010: 8). This statement presents a positive break with previous policies because it brings associations of iyoma into the conversation, although it does not address how the new training will be affected. Nevertheless, a crucial aspect affecting maternal care is governmental funding. According to a study published in 2011 by the Health Ministry and by SEGEPLAN, in recent years public expenditures dedicated to health have been under $2.5 \%$ of GDP, while funds dedicated to the Health Ministry were around 1\% (SEGEPLAN 2011). Furthermore, the study points out that these monies are mainly used in the Guatemala City and urban areas where the majority of Ladino citizens reside.

In 2007, Replogle implied a correlation between iyoma training and maternal deaths, stating that: "Guatemala appears to be an example of failed TBA training." This statement was based on the fact that although training programs had been in place for more than 50 years, the country's MMR continued to be among the highest of the Americas. Besides the problems mentioned before, another deficiency of most training programs is that they are not culturally appropriate.

\footnotetext{
12 October 2014; no data is available for 2013.

13 Translated by the author of this article from Spanish.
} 
In these trainings, for the most part, the long history of Mayan healing practices is ignored. In the last years, a few new training programs have been implemented which attempt to be more responsive to cultural and language differences, and respectful of long traditions, such as allowing iyoma to use the temascal, or to serve herbal teas to the mothers. For example, in October 2012, fifty iyoma completed a four-month long training to implement non-pharmaceutical painless childbirth techniques at the San Carlos Sija Health Center (Chaclán 2012). Remarkably, this community has not reported any case of maternal death in the last five years. Authorities from the Health Center credit this fact to the good relationship it has with its iyoma. Ana María Barrios, responsible for the San Carlos Sija Health Center, advocates for a more humane, dignified and culturally relevant childbirth, such as one that allows women to give birth while standing or kneeling.

At grass roots level, several groups of iyoma have been getting organized. Two such organizations in Sololá are the association Mayab' Ixoq' in San Pedro La Laguna, and the organization Virtud Integrada al Don de Amor, VIDA (Virtue Integrated to the Gift of Love) (Guárquez 2012). VIDA was founded in 2004 in order to share knowledge that would help reduce maternal mortality; Mayab' Ixoq' also provides technical support and leadership training. At a national level, in 2006 Alianza Nacional de Organizaciones de Mujeres Indígenas por la Salud Reproductiva, la Nutrición y la Educación (National Alliance of Indigenous Women's Organizations for Reproductive Health, Nutrition and Education) was established, being its core mission to reduce maternal mortality while promoting culturally relevant practices.

With the implementation of new laws, and the proliferation of organizations and associations concerned with maternal health issues, it would be expected that the MMRs in Guatemala would decrease, but the evidence contradicts this statement. One reason could be that even those who should be informed about new policies are often unaware of them. For example, before the 2011 general elections, members of the Red de Organizaciones de Mujeres Indígenas por la Salud Reproductiva (Network of Indigenous Women Associtations for Reproductive Health) asked several candidates who were running for political offices to sign a letter of compromise to address the difficulties of Indigenous women's health. Although all of them said they were willing to sign it, the 
majority were not aware of the existence of the law (Tecum 2011). This highlights the lack of dissemination that issues related to Indigenous women's health receive. Clearly, everyone involved should be aware of new programs and laws to ensure that they are enforced. Without enforcement, no amount of laws will make any difference.

\section{Discussion}

When it relates to matters of life and death, change never happens fast enough; yet, one can see clusters of transformation taking place in Guatemala. Reform is slowly coming from two fronts: governmental institutions and iyoma's grass roots organizations. In a little over a decade, the government has established several institutions that should improve the economic and social conditions of Indigenous women, and as a consequence, their health. Examples of these are the Comisión Presidencial Contra la Discriminación y el Racismo Contra los Pueblos Indígenas en Guatemala (Presidential Commission Against Indigenous Peoples Discrimination and Racism in Guatemala), the Unidad de Atención de la Salud de los Pueblos Indígenas e Interculturalidad (Unity of Interculturalism and Attention to Health Care of Indigenous People), the Defensoría de la Mujer Indígena (Indigenous Women's Advocacy), and the Law for Safe Motherhood. If these institutions functioned as intended and if the Safe Motherhood law were enforced, undoubtedly there would be positive consequences. Unfortunately, this is not happening as well as expected. Mayan women say that during election times politicians promise everything, but once they get elected those promises are ignored. One consequence of these failing promises is that institutions do not receive enough funding to be effective. Exceptions can be seen when international organizations provide materials or other type of aid. For example the Health Ministry supplied iyoma who successfully completed their training in with 2,350 bags of obstetric materials. Kits included scissors to cut the umbilical cord, clamps for cord clamping, gauze pads, compresses and alcohol clamp rings. These donations were made possible with support from the International Cooperation Agency of Korea (SCSPR 2012). Ideally, hospitals should provide all the 
iyoma in their area with such kits, including replacements when the supplies are exhausted.

Grass roots organizations work hard to explain the high MMRs as they understand them, and to improve the situation. When iyoma were blamed for the high mortality ratio, they united and pushed for reform. They claimed that MMRs were influenced to some extent by the lack of cultural competence on the part of the training personnel and biomedical practitioners. Since 2011 Mayab' Ixoqi' has arranged meetings for iyoma and other healers for support and training. This organization also provides iyoma with information about their legal rights. Organizations across the country are facilitating conversations among iyoma to share their ancestral knowledge and provide recommendations to official institutions. One recommendation resulted in the creation of health centers where both types of knowledge, biomedical and traditional, can be offered to mothers who choose according to their preferences (Gran Confederación de Consejos de Principales Ajq'iab' Originarios Mayab’ de Guatemala 2010). In 2012, a labor and delivery center in Chimaltenango was established, where iyoma were allowed to do their job (Rosales 2012). German and local funds contributed to building this center, where Indigenous culture would be respected. In August 2012, iyoma from different communities from Sololá got together to share ideas about how to help their patients and avoid women's deaths (Julajuj 2012). These types of activities are taking place more frequently.

As it can be seen, in several sectors, iyoma are being recognized as an integral part to mothers' health (Berry 2010). Some governmental institutions have also recognized iyoma's work, acknowledging that without their help many women who live in remote areas would have to deliver by themselves (SEGEPLAN 2010). The Health Ministry also acknowledged that in order to reduce maternal deaths it was necessary to work towards educating and empowering women -so they could make informed decissions- while striving to help them improve their socioeconomic situation. Finally, the last goal was to bring an interculturality perspective to maternal health care (Ministerio de Salud Pública y Asistencia Social 2011). The UNFPA also recognized this last goal asserting, "it is urgent to strengthen health systems from traditional services providers, especially 
favoring the recognition of iyoma in their intercultural roles and as communities' mobilizers in favor of the overall health of women" (1).

It is clear that as Guatemala struggles to reduce its MMRs, iyoma are doing much more than taking care of expectant mothers and helping them through their delivery and postpartum periods. They are getting out of their comfort zones and organizing themselves to bring about the change that will reduce maternal deaths. It is easy for this country's Postcolonial elites to blame iyoma for the high MMR suffered by Mayan women, when in reality the situation reflects instead systemic problems inherited from Colonial times. Centuries after the Spanish colonization implemented structures of discrimination and disregard for Indigenous people, these socioeconomical and cultural constructions continue in place, due to an effort to perpetuate systems that keep Indigenous people poor and illiterate. The situation is even worse for women as they are marked by a triple subalternity. Patriarchy and Colonialism were welded together. During Colonial times, women, and even more so Indigenous women, were considered property of their owners, without rights or a voice. Patriarchy is still strong in a so-called Postcolonial Guatemala, where conditions experienced by the Other/Female receive minimal attention. The policies and laws of the country regarding mothers' health have changed, but the willingness to implement these does not seem to be as pervasive as it would be desirable. Segments of the medical establishment appear unwilling to accomodate Mayan requests, even those that do not challenge biomedical principles, such as the standing position for giving birth, or others that have been proven to be more effective than the biomedical alternatives, such as traditional ways of cauterazing the umbilical stump (Jordan 1990). Jordan writes, "traditional methods for dealing with the dangers of childbirth are dismissed out-of-hand, without regard to any objective efficacy they might have" (Jordan: 100) The reasons for these type of behaviors go back hundreds of years.

The refusal by many hospitals to accept traditional positions for birthing is symptomatic of the powerlessness of women within them, and of the colonizing and patriarchal norms of these institutions. As Michel Foucault stated, the body is the place where power is exercised, and the pregnant body within patriarchal social systems is not 
an exception. Hospitals are one of the spaces where "medical colonization," as described by Arthur W Frank (1997: 10), is most apparent. Frank writes, "Just as political and economical colonialism took over geographic areas, modernist medicine claimed the body of its patients as its territory" (10). Once they are admitted to the hospital, MayanTz'utujil women will be immersed in an unknown system where even in the $21^{\text {st }}$ century their bodies will experience the effects of Colonialism, where they will be treated as Cultural Other, disconnected, unrecognized, and powerless.

We must keep in mind that in rural Mayan-Tz'utujil communities the tradition is that women give birth at home, as the women interviewed expressed. In their culture birth is not a disease. Thus, when an iyom insists that the parturient go to a hospital, it is because the situation is grave. Rural pregnant, Indigenous women who are admitted in hospital are already concerned for their lives and the life of their unborn child. They are distressed, frightened and might be experiencing lacerating pain. In their rural communities their culture is the norm. In hospital, they will abruptly enter a culture they do not understand. Not only do medical practitioners not understand their language, but mothers-to-be are discriminated against and humilitated for not being able to communicate in the language of the poweful. Together with language, which shapes our self-expression and allows us to communicate with our family and friends, spirituality is one of the most defining aspect of a group's culture. In hospital, women's spirituality is also disregarded. Beyond that, other aspects that define their culture are marginalized. They are required to get out of their handwoven clothes and to forego their modesty. Ignored are their desired position for delivery, their will to keep their placenta, and to use the temascal. Even something as simple as the tradition of receiving a cup of hot herbal tea after delivery is disregarded. Furthermore, they are separated from their support group, their iyom, family, and closer friends. Their older children are kept away. Their husbands might not have the money for transportation to go to hospital. If the women dare to complain, they are treated as difficult. If they don't know how to act, they are treated as children. A primipara might feel guitlty because she is not able to fulfill her mother-inlaw's wishes of helping her deliver her first grandchild. It is not surprising that Indigenous women are reluctant to give birth in hospitals. These mothers-to-be do not phrase it in 
these terms, but their refusal to be hospitalized denotes their will to fight a colonial system that degrades them.

As Guatemala attempts to fight its high MMRs, one issue is the lack of facilities in rural areas -and the insufficient or inadecuate roads to reach them. Bailey et al. write, "Women with obstetric complications must also have access to essential obstetric services and want to use these services" (21). The fact that the country does not have enough rural facilities to accommodate all problematic births, let alone all births, is a tragedy; another fact is that even if it did, Indigenous women might not want to deliver their children there.

Guatemala is a country that in many aspects is still entrenched in the Colonial period. This nation became independent in 1821, but many of the structures of that time continue to be in place. Some are evident, such as the control of the land by a few wealthy families, the economic disparities between Ladinos and Indigenous people, the predominance of Christian religions over Indigenous spirituality, the hegemony of Western ways of knowledge over Indigenous ones, and of the Spanish language over Mayan, Xinca or Garifuna languages.

At the same time, as it is distinctive of a Postcolonial society, Guatemala is characterized by the struggle between those who insist in the perpetuation of hierarchical social Colonial structures, and those who strive to end years of domination by decolonizing their society by removing the remnants and effects of the Colonial Period. Not every institution remains unchanged, as some are transforming. Currently, public education is taught in both Spanish and the child's language. Mayan spirituality is slowly achieving a status it has not had for almost 500 years; for example, every archeological site has a place to hold Mayan ceremonies. On the other hand, other institutions, have been hardly challenged. This is the case of medicine, since most people do not to perceive it as a tool of the empire.

Cunningham writes that just like language, religion, economic structures and political systems which were imposed on the colonies, biomedical knowledge was also implemented without any regard for the medicinal systems that were already in place (1997). The objective of imposing the institutions of empire in the colonies was one of 
control, that is, to have power over Indigenous people. The same is true of biomedical medicine since it is postulated in a system of dichotomies, Cunningham claims. Western medicine is superior when it is contrasted with the knowledge of iyoma, given that according to Colonial and Postcolonial societies its attributes have the positive signs agreed upon: male over female, Ladino over Indigenous, rich over poor, scientific over spiritual, modern over traditional, urban over rural. Biomedical practices have hegemony over other medical practices, which cannot be questioned. If they did, it would mean relinquishing some of their power.

The biomedical health system's unwillingness to share its power is evidenced by the fact that the structure of Guatemala's health system has remained largely unchanged since the implementation of Western medicine. As Packard points out (2003), the priority of European rulers was the health of the white population and the Indigenous work force; thus, health centers were located close to the cities, where whites resided, and to areas of production. Concern for rural Indigenous populations was not prevalent, which resulted in the lack of services in the countryside. While Packard writes about unspecified colonial societies, it is clear that these conditions apply to Guatemala today. He writes, "Rural health services, which served the needs of local populations, were run by missionaries and focused primarily on maternal and child health," (2003: 99). Missionary-provided health care can be expanded today to include non-governmental and international agencies. Other characteristics of colonial medicine were the contempt and even persecution of Indigenous health care providers, which Spaniards first, and Ladinos later, branded as witches, warlocks and servants of the devil. Even today it is not uncommon to hear practitioners of other religions classify the rites and methods of sacred healers as the "devils' work."

Packard writes that among biomedical personnel, doctors are usually the least willing to integrate biomedical and traditional healing methods (Packard 2003). Doctors tend to believe that the scientific method is the only way to acquire objective truth and consequently, they have difficulty understanding that there might be other ways of knowledge; thus, integration of iyoma's techniques has been limited to those practices that fall within Western medicine's parameters. This type of conflict can be found also at 
the Health Ministry. Ishida writes, "The MSPAS assumes that its advice should be privileged; considering the context in which the modern midwife practices, it is difficult to understand why that would be so" (Ishida, Stupp, Turcios-Ruiz, \& Daniel B. William 2012: 154). In general, iyoma approach new techniques in a different way. As long as their knowledge is not disrespected, they are willing to try new methods. The same situation is not applicable to doctors. For the most part, it is very difficult for them to reliquish any power, even when it only means allowing the midwife to attend the delivery. This is tragic, since in order to benefit the health of their patients, even if health care professionals are trained in the scientifc method, it would be best for their patients if biomedical practicioners could exercise some suspension of disbelief in their interactions with iyoma.

Robbie Davis-Floyd analyzes what she calls "post-modern iyoma." She defines them as "relativistic, articulate, organized, political, and highly conscious of both their cultural uniqueness and their global importance" (2005: 13). Many Mayan iyoma fit this description. They understand there is more than one way to acquire knowledge, including "different ways of knowing about birth, discrepant systems that often conflict but can be complementary" (169). It is remarkable that objections to Postcolonial biomedical biases have come mainly from Indigenous, poor and illiterate women who are also aware of the critical time they are living in, and of the impact they are having. It is also interesting that these women are starting to be succesful at cracking the monolithic structure of biomedical institutions and helping define what a 21 st century health system can be in a multicultural society.

To reduce maternal deaths, a paradigm shift is required. Iyoma must be admitted to the table were all stakeholders discuss probable solutions. Iyoma possess knowledge invisible to others. They are the ones who best know their patients, the problems they face, and the reasons why they avoid hospitals and biomedical professionals. A move towards decolonizing the health system would be to accept those who have been previously marginalized. As Pauline Lipman writes, "The authority to frame debates on social issues limits the range of options available" (2009: 160). Once iyoma are accepted, their voices will articulate opportunities for improving rural, Indigenous women's health. 
Unquestionably, a paradigm shift is needed among biomedical stakeholders and the community at large in relation to both traditional birth attendants and their patients. Indigenous women's reproductive health will not improve until this happens and the biomedical healthcare system is decolonized.

\section{References}

Bailey, Patricia; José Szászdi and Lucinda Glover. 2001. “Obstetric complications: Does training traditional birth attendants make a difference?" Revista Panamericana De Salud Publica, 11 1: 15-23. http://www.scielosp.org/pdf/rpsp/v11n1/7884.pdf [15 Aug. 2014].

Baines, C. C. 1950. “Children Born with a Caul,” Folklore, 61, 2: 104.

Baldwin, Laura Mae, Heidi L. Hutchinson and Roger A. Rosenblatt. 1992. "Professional relationships between midwives and physicians: Collaboration or conflict?". American Journal of Public Health, 82, 2: 262-264.

Berry, Nicole S. 2006. "Kaqchikel midwives, home births, and emergency obstetric referrals in Guatemala: Contextualizing the choice to stay at home." Social Science \& Medicine, 62, 8: 1958-1969.

2010. Unsafe Motherhood: Mayan Maternal Mortality and Subjectivity in Post-War Guatemala. New York: Berghahn Books.

Centro Nacional de Análisis y Documentación Judicial. 2010. Ley para la Maternidad Saludable. Decreto número 32-2010. http://www.oj.gob.gt/es/QueEsOJ/EstructuraOJ/UnidadesAdministrativas/Centro AnalisisDocumentacionJudicial/cds/CDs\%20leyes/2010/pdfs/decretos/D0322010.pdf [25 Jan. 2012].

Chaclán, Ana C. 5 October 2012. Aprenden sobre parto sin dolor. Prensa Libre. http://www.prensalibre.com/quetzaltenango/Aprenden-partodolor_0_786521392.html [20 Jan. 2013].

Chary, Anita, et al. 2013. "The changing role of Indigenous lay midwives in Guatemala: New frameworks for analysis.” Midwifery, 29, 8, 852-858.

Cifras para el Desarrollo Humano. n.d. “Zacapa. Características Básicas.” Colección estadística departamental. Programa de los Informes Nacionales de Desarrollo Humano $y$ Objetivos del Milenio. Guatemala. http://www.desarrollohumano.org.gt/fasciculos/cifras_v4.html [4 Oct. 2014]. 
Cosminsky, Sheila. 2001. "Maya Midwives of Southern Mexico and Guatemala." Mesoamerican Healers. Eds. Brad R. Huber \& Alan R. Sandstrom. Austin, TX: University of Texas Press. 179-210.

Cunningham, Andrew. 1997. "Introduction: Western medicine as contested knowledge." Western medicine as contested knowledge. Eds. Andrew Cunningham and Bridie Andrews. New York: Manchester University Press: 1-23.

Davis-Floyd, Robbie. 2008. "Daughter of time: the postmodern midwife." Revista da Escola de Enfermagem, 42, 1: 168-72.

de León, Susana. 7 October 2012,. "La abuela comadrona Gertrudis." El Periódico. Guatemala. http://www.elperiodico.com.gt/es/20121007/domingo/218894 [18 Jan. 2014].

Frank, Arthur W. 1997. The wounded storyteller: Body, illness, and ethics. Chicago: University of Chicago Press.

Giralt, Alicia. 2012. "A Decade after Guatemala's Agreement on Identity and Rights of Indigenous Peoples: Mayan-Tz'utujil Women's Views on Health, Healing and Disease." Health Care for Women International, 33, 5: 440-456.

Goldman, Noreen, and Dana A. Gleib. 2003. "Evaluation of midwifery care: results from a survey in rural Guatemala." Social Science \& Medicine, 56: 685-700.

Gran Confederación de Consejos de Principales Ajq'iab' Originarios Mayab' de Guatemala. 2010. Informe Diálogo y Consulta Intercultural con Abuelas Comadronas de Guatemala. http://www.scribd.com/doc/102297037/ReporteComadronas-UASPII-2010 [28 June 2013].

Guárquez, Alonso. 31 August 2012. "Comadronas compartieron experiencias." Noticias de Guatemala: http://noticias.com.gt/departamentales/20120903-sololacomadronas-compartieron-experiencias.html [27 Jun. 2013].

Hurtado, Elena, and Eugenia Sáenz de Tejada, E. 2001. "Relations between Government Health Workers and Traditional Midwives of Guatemala." Mesoamerican Healers. Eds. In Brad R. Huber \& Alan R. Sandstrom. Austin: University of Texas Press: 211-242.

Instituto Nacional de Estadística. Guatemala: Estimaciones de la Población total por municipio. http://www.oj.gob.gt/estadisticaj/files/poblacion-total-pormunicipio1.pdf. [2 Oct. 2014].

Ishida, K., Stupp, P., Turcios-Ruiz, R., \& D. B. William, A. E. 2012. "Ethnic Inequality in Guatemalan Women's Use of Modern Reproductive Health Care.” International Perspectives on Sexual and Reproductive Health, 38, 2: 99-108.

Jordan, Brigitte. 1990. "Technology and the Social Distribution of Knowledge: Issues for Primary Health Care in Developing Countries." Anthropology and Primary Health 
Care. Eds. Jeannine Coreil and J. Dennis Mull. Boulder, CU: Westview Press. 98120.

Julajuj, Angel. 15 November 2010. “Comadronas reclaman derechos.” Prensa Libre. http://www.prensalibre.com/noticias/Comadronas-reclamanderechos_0_372562801.html [22 Sept. 2013].

. 2012, August 27. "Intercambian ideas para atender partos." Prensa Libre. http://www.prensalibre.com/solola/Intercambian-ideas-atenderpartos_0_763123699.html [25 Sept. 2013].

Lang, Jennifer. B. and Elizabeth D. Elkin. 1997. "A Study of the Beliefs and Birthing Practices of Traditional Midwives in Rural Guatemala." Journal of NurseMidwifery, 42, 1: 25-31.

Lipman, Pauline. 2009. "Politics by Other Means. Education Accountability and the Surveillance State." Schools under surveillance: Cultures of control in public education. Eds. Torin Monahan and Rodolfo D. Torres. New Brunswick: Rutgers University Press: 159-174.

Global Health Observatory. 2014. "Maternal mortality country profiles." World Health Organization. 2014. http://www.who.int/gho/maternal_health/countries/en [1 Oct. 2014].

MDG Monitor. 2007. Improve Maternal Health. Tracking the Millenium Development Goals. http://www.mdgmonitor.org/goal5.cfm. [16 Sept. 2013]

Media Centre. 2011, June 20. 'More skilled midwives needed to save women's and newborns' lives." World Health Organization. http://www.who.int/mediacentre/news/releases/2011/midwifery_report_20110620 /en/index.html [20 June 2012].

Newman, Barbara and Leslie Newman. 1939. "Some birth customs in East Anglia." Folklore, 50 2: 176-187.

Office of the High Commissioner for Human Rights in Guatemala. 2009. United Nations Human Rights in Guatemala http://www.ohchr.org/EN/Countries/LACRegion/Pages/GTSummary0809.aspx [22 June 2012].

Organización Panamericana de la Salud/Organización Mundial de la Salud, Guatemala. 2009, November 16. En Guatemala se logra Acuerdo de Salud con los Pueblos Indígenas. $\quad O . \quad P . \quad$ Salud. http://new.paho.org/gut/index.php?option=com_content\&task=view\&id=148\&Ite mid $=259$ [5 Oct. 2012].

Packard, Randall M. 2003. "Post-Colonial Medicine." Companion Encyclopedia of Medicine in the Twentieth Century. Roger A. Cooter. New York: Routledge: 97112. 
Pan American Health Organization. 2001. "Guatemala. Country Chapter Summary from Health in the Americas, 1998." Health Situation Analysis and Trends Summary. Pan American Health Organization. http://www.paho.org/english/sha/prflgut.htm [6 Oct. 2013].

Paul, Lois. 1975. "Recruitment to a ritual role: The midwife in a Maya community." Ethos, 3, 3: 449-467.

Paul, Lois, and Paul Benjamin D. 1975. "The Maya midwife as sacred specialist: A Guatemalan case." American Ethnologist, 2, 4: 707-726.

United States Institute of Peace. 1995. Agreement on identity and rights of Indigenous people. United States Institute of Peace. http://www.usip.org/files/file/resources/collections/peace_agreements/guat_95033 1.pdf [1 Aug. 2013].

. 1998. "Agreement on identity and rights of Indigenous people." Peace Agreements: Guatemala. http://www.c-r.org/our-work/accord/guatemala/identityrights.php [1 Aug. 2013].

Reiger, Kerreen M. and Karen L Lane. 2009. "Working together: collaboration between midwives and doctors in public hospitals." Australian Health Review, 33, 2: 315324.

Replogle, Jill. 2007. "Training traditional birth attendants in Guatemala." The Lancet, 369: $177-178$

Reynolds, Louisa. 2010, May 20. "Comadronas indígenas luchan por derechos reproductivos." Comunicaciones Aliadas. http://www.noticiasaliadas.org/articles.asp?art=6136\# [25 Oct. 2013].

Rogoff, Barbara. 2011. Developing destinies. A Mayan midwife and town. NY: Oxford University Press.

Rosales, J. 1 August 2012. "Comadronas abren centro de atención." Prensa Libre. http://www.prensalibre.com/chimaltenango/Comadronas-abren-centroatencion_0_747525279.html [25 Oct 2012].

Schieber, Barbara. 17 May 2008. "Las comadronas tradicionales mayas y ladinas en Guatemala." The Guatemala Times. http://www.guatemalatimes.com/espanol/barbarita/213-las-comadronastradicionales-mayas-y-ladinas-en-guatemala-i.html [26 Oct 2012].

Secretaría de Comunicación Social de la Presidencia de la República. 2012, June 27. "Salud entregara maletines obstetricos a comadronas." Gobierno de Guatemala. http://www.guatemala.gob.gt/index.php/2011-08-04-18-06-26/item/826-saludentregara-maletines-obstetricos-a-comadronas [5 Oct. 2012]. 
SEGEPLAN. 2010. Tercer informe de avances en el cumplimiento de los objetivos de desarrollo del milenio. http://undp.org.gt/data/publicacion/III\%20Informe\%20ODM,\%20web.pdf [27 Oct 2012].

2011 A. Estudio Nacional de Mortalidad Materna. Informe Final. Ministerio de Salud Pública y Asistencia Social. Guatemala: Serviprensa.

\section{Guatemala.}

2011 B. Presentan Estudio Nacional de Mortalidad Materna. Gobierno de http://www.SEGEPLAN.gob.gt/2.0/index.php?option=com_content\&view=article \&id=766:presentan-estudio-nacional-de-mortalidadmaterna\&catid $=25$ :ultima\&Itemid $=115$ [8 Oct. 2012].

. 2014. Informe de Avances 2013. Política de Desarrollo Social y Población. http://www.segeplan.gob.gt/downloads/PDSP/InfPD2013.pdf [1 Oct 2014].

Tecum, Hector Javier. 2011. La salud de las mujeres indígenas en las elecciones recientes. Americas Quarterly. http://americasquarterly.org/node/2917 [15 Oct. 2012].

Office of the High Commissioner for Human Rights. 1996-2012. "OHCHR in Guatemala" UN Human Rights Chief in Guatemala. http://www.ohchr.org/en/Countries/LACRegion/Pages/GTSummary0809.aspx [4 Oct. 2013].

United Nations Fund for Population Activities, Guatemala. 2012. Las comadronas tradicionales, agentes de desarrollo. Guatemala. http://www.unfpa.org.gt/content/las-comadronas-tradicionales-agentes-dedesarrollo [4 Oct. 2013].

Valladares, Danilo. 2012, June 4. Midwives Play Key Social Role in Guatemala. Inter Press Service. http://www.ipsnews.net/2012/06/midwives-play-key-social-role-inguatemala [6 Oct. 2012]. 